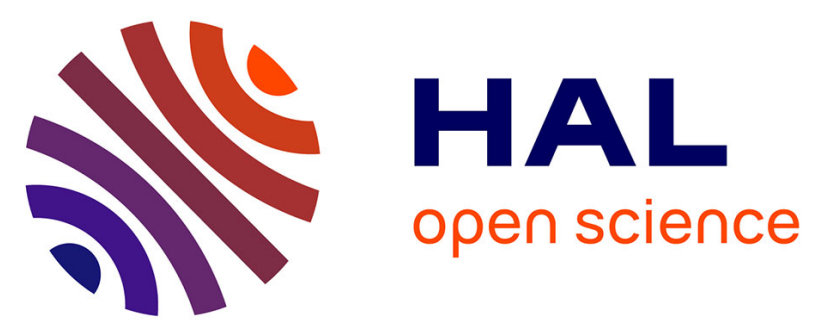

\title{
Risk factors for return visits and rehospitalizations to the child emergency psychiatric unit: A retrospective study over 2 years at Saint-Étienne University Hospital
}

\author{
A. Gay, M. Peyrard, P. Pineau, J. Pellet, B. Trombert-Paviot, C. Massoubre
}

\section{- To cite this version:}

A. Gay, M. Peyrard, P. Pineau, J. Pellet, B. Trombert-Paviot, et al.. Risk factors for return visits and rehospitalizations to the child emergency psychiatric unit: A retrospective study over 2 years at Saint-Étienne University Hospital. L'Encéphale, 2019, 45, pp.468 - 473. 10.1016/j.encep.2019.03.005 . hal-03488421

\section{HAL Id: hal-03488421 \\ https://hal.science/hal-03488421}

Submitted on 21 Dec 2021

HAL is a multi-disciplinary open access archive for the deposit and dissemination of scientific research documents, whether they are published or not. The documents may come from teaching and research institutions in France or abroad, or from public or private research centers.
L'archive ouverte pluridisciplinaire HAL, est destinée au dépôt et à la diffusion de documents scientifiques de niveau recherche, publiés ou non, émanant des établissements d'enseignement et de recherche français ou étrangers, des laboratoires publics ou privés.

\section{(c) (1) $\$$}

Distributed under a Creative Commons Attribution - NonCommerciall 4.0 International 


\section{Risk factors for return visits and rehospitalizations to the child emergency psychiatric unit: a retrospective study over 2 years at Saint-Etienne University Hospital}

\section{Aurélia Gay ${ }^{1}$, MarlènePeyrard ${ }^{1}$, Patrick Pineau ${ }^{1}$, Jacques Pellet ${ }^{1 *}$, BéatriceTrombert-Paviot ${ }^{2}$, Massoubre Catherine ${ }^{1}$}

1 - department of psychiatry, CHU de Saint-Etienne, mail: aurelia.gay@chu-st-etienne.fr

2 - , MD, PhD, department of medical information, CHU de Saint-Etienne, mail

* Pour correspondance : Jacques Pellet

department of psychiatry, CHU de Saint-Etienne

mail : jacques.pellet.42@gmail.com

There is no conflict of interest for every author of this article, for this article 


\title{
Risk factors for return visits and rehospitalizations to the child emergency psychiatric unit: a retrospective study over 2 years at Saint-Etienne University Hospital
}

\begin{abstract}
Purpose: This retrospective study aimed to achieve a better understanding of risk factors leading children and adolescents hospitalized in an emergency psychiatric ward to return visits, and to propose preventive devices. Method: From January 2, 2010 through February 29, 2012, 180 children and adolescents younger than 17 years were hospitalized in a total of 261 stays in the emergency psychiatric ward of University hospital of Saint-Etienne (France). We assessed clinical and sociodemographic characteristics of these patients and traced any of their return visits to the same unit through December 31, 2012. Risk factors for patients' repeated visits were calculated using multivariate analysis, and the cumulative incidence of returns using the Kaplan-Meier method for censored data. We used confidence interval of relative risk, considering 0.05 to reflect significance. Results: Over the 2 years of the study, $77(42.8 \%)$ of the 180 patients revisited the emergency psychiatric ward; 62 ( 80 , $7 \%$ ) of these required further hospitalizations. Multivariate analysis linked the patients' psychiatric history (RR = $2.5)$ and pursuit of vocational education $(R R=4)$ with the risk of return. Return visits rose from $27.2 \%$ at 6 months to $41.2 \%$ at 2 years. Conclusion: Knowledge of risk factors would allow implementation of secondary or tertiary preventive devices. Students could undergo early screening of psychiatric pathologies using mobile screening teams which would save money, avoid hospitalizations, and when necessary, facilitate both hospitalization and return visits.
\end{abstract}

Keywords: adolescent; psychiatry; emergency unit; hospitalization; risk factors; returns

\section{Introduction}

In 2003 the French National Institute of Health and Medical Research (INSERM) reported that one in eight children in France had a mental disorder [1], and although French infant and adolescent psychiatry arose as a medical discipline in the mid-1930s, challenges remain that prevent most of these young people from obtaining adequate treatment. Issues include a limited number of available hospitals with specialized care, hospital stays which are not long enough for proper care to be given, and prolonged waiting periods for attention in ambulatory care facilities [2-7] which lead to increased consultations in general emergency wards as families and institutions recognize no viable alternative $[8,9]$. Most such consultations involve adolescents, usually defined as no older than 15 years and 3 months [10-12], who are in a time of psychological readjustment. Their symptoms may be acute, and attempted suicide is common. Suicide is the second most frequent cause of death among teenagers in France $[13,14]$. In addition, uncertainty regarding the paediatric or adult status of these individuals can delay timely admission in emergency wards. Generally, a psychiatrist should be on the emergency staff to quickly assess possible situations within his or her expertise, initiate appropriate treatment, and support the efforts of other caregivers [15-19]. When hospitalization is required, child psychiatric wards are often crowded, or paediatric departments are reluctant to accept this at-risk population. Although the Hospital of Saint-Etienne University established a 12-bed psychiatric emergency ward in 1979, less than $1 \%$ of its patients have been 
young people [20]. The addition of a 4-bed unit dedicated to young patients in February 2010 permitted greater accessibility of specialized attention for this population. A child psychiatrist interviews the young patient and his/her parents, and the young person can generally be admitted to the hospital after no more than one hour and a half. Hospitalization offers these young patients a stability "protective shield" and relief from their suffering and allows for implementation of therapeutic strategies [21,22]. Located near the emergency pediatric department and in the same building as the general emergency department, the facility is open 24 hours a day, 7 days a week, and 365 days a year.

We retrospectively evaluated characteristics of patients who paid multiple visits to emergency facilities for consultation and/or hospitalization after an index hospitalization, and propose possible strategies to avoid this burden. We assessed risk factors for patients' repeated visits to our psychiatric emergency unit. Additionally, we examined comprehensive data of all these patients.

\section{Materials and Methods}

We evaluated medical records of all 180 patients younger than 17 years who were hospitalized at Saint Etienne either in our 4-bed pediatric unit or adult beds requisitioned by the hospital's executive director from January 2 , 2010 through February 29, 2012 and traced any return visits of these individuals to the psychiatric emergency unit through December 31, 2012. We did not include patients who underwent simple consultation in the unit or who were hospitalized outside the emergency department. We recorded age, sex, place of residence, parental marital status, number of years of education, and results of psychosocial prescription as well their personal and familial history of somatic, psychiatric, or psychosocial problems, rape or sexual abuse, and previous general therapies or psychiatry-related treatments, and existence of criminal record. For each hospitalization, we recorded the reason for and date of admission, referring person, type of hospitalization, interval between consultation and hospitalization, requisitioned bed, receipt of social or legal assistance, receipt of drug treatment, requirement for physical restraint, and adverse events related to the hospitalization.

In addition, we recorded the ICD-10 classification of mental and behavioral disorders using the blue book and known diagnoses, therapeutic orientation at discharge, whether they returned home, were hospitalized in the psychiatric ward, underwent psychiatric consultation/s, or received other therapies. If they returned to the psychiatric emergency ward, we noted whether it was for consultation and/or hospitalization and the date of the visit.

We anonymized data in an Excel spreadsheet and calculated statistics using Statistical Analysis System (SAS) software (Version 9.2, SAS Institute, Inc., Cary, North Carolina, USA). Descriptive analyses of qualitative variables concerning patients and hospitalizations were presented as percentages and frequencies and those of quantitative variables, as averages and standard deviations. Analyses of sociodemographic data took into account only the first stay, and analyses of hospitalization considered all stays. We calculated the cumulative incidence of returns using the Kaplan-Meier method for censored data, using the time between discharge from the hospital and the first return to the emergency psychiatric ward. We assessed the degree of association by 
confidence interval of relative risk, considering 0.05 to reflect significance. The ethics committee of the hospital accepted the protocol ( $\mathrm{n}^{\circ}:$ IRBN082019/CHUSTE)

\section{Results}

Figure 1 (insert) presents flow charts of the patients' first stay and return visits to the emergency psychiatric ward. Over the two years of the study, 180 children and adolescents were hospitalized in a total of 340 stays (180 first stays and 160 rehospitalisations) and 71 consultations; 77 (42.8\%) of the 180 revisited the emergency psychiatric ward, and $62(80,5 \%)$ of these required further hospitalizations.

Table 1 (insert) summarizes the patients' sociodemographic data. The 180 patients comprised slightly more girls $(n=97)$ than boys $(n=84)$, and almost two-thirds $(n=115)$ were between 15 and 17 years of age. Most attended regular schools. Half of the patients had frequently undergone court-ordered psychosocial prescription. Asthma and epilepsy were the primary somatic problems. Psychiatric histories were not detailed, but psychotropic treatments at the time of hospitalization were : no treatment : $n=81$ (45\%); antipsychotic drugs : $n=49(27,2 \%)$; antidepressant drugs : $n=11(6 \%)$ associated 2 times to antipsychotics; benzodiazepines : $n=35(19,4 \%)$ associated 8 times to antidepressant; mood stabilisers : $n=6(3,3 \%)$; psychostimulants : $n=4(2,2 \%)$.

The main diagnoses were as follows: pervasive developmental disorders: 33 (18,33\%); depressive episodes: 26 (14,44\%); specific personality disorders: 20 (11,11\%); adjustment disorders: 12 (6,7 \%); mixed disorders of conduct and emotions: 10 (5,5\%); mental and behavioral disorders due to use of alcohol, opioids, cannabis and substances: 9 (5\%); conduct disorders confined to the family context : 7 (3,9\%); schizophrenia: 6 (3,3\%); acute and transient psychotic disorders: 6 (3,3\%); other disorders of psychological development: 5 (2,8 \%); Unspecified disorder of psychological development: 4 (2, 2\%) ; Dissociative disorders: 3 (1,7\%); Phobic anxiety disorder of childhood: 3 (1,7 \%) ; Generalized anxiety disorder: 2 (1,1\%) ;_Acute stress reaction: 1 (0, 5\%) ; Anorexia nervosa : 1 (0,5 \%) ;_Hyperkinetic disorder: 1 (0,5\%) ; Mild mental retardation: 1 (0,5 \%) ; missing or not reliable: 30 (17\%).

Parents of 100 children were separated, and family psychiatric history included, sometimes cumulatively, alcoholism and delusional and personality disorders. Domestic violence against the wife and children were notable.

Table 2 (insert) delineates the reasons for patients' hospitalizations, shows the reasons about the patients' hospital stays and orientation after discharge. About half were referred for behavioural disorders, $46 \%$ by physicians (treating psychiatrist, hospital services, and other physicians) and $42 \%$ by family members or social workers. Patients were admitted mainly on Mondays and Wednesdays, more than 25 in March, May, and October and fewer than 20 in July and December. Application for admission was signed by parents in $89.2 \%$ of cases and implemented into the form of an interim placement order in $7 \%$, or at the request of an official representative of competent public authorities in the remaining cases. Admission followed consultation on the same day in $83 \%$ of the cases. 
Hospitalizations averaged 7.2 days ( 1 to 39 days), and staffs were authorized to apply physical restraint if deemed necessary. Pervasive developmental, behavioural disorders, personality, and mood disorders accounted for $43,88 \%$ of diagnoses. Most patients returned home, but one-fifth were transferred to psychiatric services.

\section{Risk factors for return to psychiatric emergency services}

Table 3 (insert) shows frequency of returns to the emergency psychiatric unit according to patients' sociodemographic characteristics. Average age did not differ between those who visited the psychiatric emergency unit once or multiple times. Univariate analysis associated risk factors for return visit/s with vocational educational level, but with only borderline statistical significance. Clinical variables with associated risk of return included the patient's psychiatric history, hospitalization or consultation in a psychiatric adolescent unit, initial treatment with antipsychotic medication/s and treatment at discharge, court-ordered placement, and hospitalization motivated by suicide attempt. Multivariate analysis significantly linked the patients' psychiatric history $(R R=2.5)$ and pursuit of vocational education $(R R=4)$ with the risk of return.

\section{Cumulative incidence}

Figure 2 (insert) shows cumulative incidence for first returns to psychiatric emergencies in function of time. The mean duration of observation was 750 days in the groups with and without return without significant difference. Return visits rose from $27.2 \%$ at 6 months to $41.2 \%$ at 2 years, and the cumulative incidence of returns with hospitalization was about $10 \%$ higher than for single consultations at 6 months, one year, and two years. Table (4)

\section{Discussion}

The rate of hospitalization among our patients was roughly comparable to those found in the literature [20,2325], although we encountered more female patients [26-36]. Admissions were more frequent on Mondays and Wednesdays, less frequent on weekends, and showed seasonal peaks in the spring and autumn, findings in accordance with those of other reports $[33,35,36]$. Nevertheless, some $[2,37,33,34,38]$ have reported more frequent admissions in the evening and on weekends. Fewer of our patients were referred by family to psychiatric emergency than the numbers reported elsewhere $[3,11,24,32,33,36]$. Conversely, medical doctors have referred patients to psychiatric emergency facilities to facilitate expert consultation in response to crowding in ambulatory care facilities. Rates of separation/divorce [30, 32, 39] and history of family psychiatric disorders [32,39] among our patients were mainly consistent with those in the literature but lower than those found by Incarnazzo (33\%) [40], Lee (31\%) [41] and Pacheco (37\%) [30], which is perhaps partly explained by differences in socioeconomic level, number of parents present in the home, and history of psychiatric disorders in families among the populations described.

Similar to the findings of Nadereau and colleagues [39], about half of our adolescents receive educational setting, court-ordered placement, or assistance in the community. In addition, those with psychiatric disorders and psychic suffering- as many as $30 \%$ in those reported by Stewart and associates [42] - who receive psychiatric 
care also benefit from child welfare services or placement in foster families or children's homes $[4,6,38,43]$. However, poorly qualified personnel and inappropriate individualized response to children's needs in these institutions can result in frustration and subsequent violence [33,34] and lead to more intense use of psychiatric emergency consultations.

Data concerning family psychiatry history are rarely reported in articles concerning adolescents and emergency psychiatry. Nevertheless the teams of Pacheco [30], Grupp-Phelan [44], and Laget [29] reported similar results to ours.

Adolescents presenting with psychiatric pathologies often come to the emergency ward in crisis because of their poor compliance with prescribed psychiatric care and drug treatment. For adolescents with a personal psychiatric history, several studies $[27,43,45,46]$ have shown a relative risk of return to emergency of 2.5. We did not include some patients whose diagnoses were unreliable, because data were missing or not reliable. Nevertheless, we reported, as have others, the presence of psychotic, mood, but not addictive disorders as possible risk factors for return visits to emergency $[43,44]$. Christodulu and associates [46] indicated adaptation disorders, behaviour disorders, and acting out as such factors contrarily to others studies [43, 45, 46]. Multivariate analysis does not support the protective role of educational measures and psychotropic treatment.

The relative risk for return to emergency is 4 for adolescents enrolled in vocational education. We found no data in the literature on this topic, but numerous authors have emphasized that about $30 \%$ of pupils who fail in school receive psychiatric care $[3,26,35,41]$ and, in France, those who fail in school are often enrolled in this type of education.

Knowledge of risk factors would allow implementation of secondary or tertiary preventive devices. Students could undergo early screening of psychiatric pathologies by their general practitioners or trained nurses, and implementation of mobile screening teams, such as that of Saint-Etienne, might, in future, save money, avoid hospitalizations, and when necessary, facilitate both hospitalization and return visits to the emergency psychiatric ward.

Few articles address psychiatric hospitalization in adolescents, and our study is limited by its retrospective nature and its conduct in a single institution. Data regarding diagnoses and type of hospitalization were sometimes missing, and our sample size was small. Future prospective multicentre studies might provide more comprehensive data permitting more accurate multivariate analysis.

\section{Conclusion}

Most of the young patients hospitalized in our emergency psychiatric unit were adolescents. Many had a personal and family psychiatric history, and many had undergone frequent drug treatment. Hospitalization was often related to behaviour and psychotic disorders. Minor children were easily referred to the emergency psychiatric unit because of its accessibility. Frequency of returns tended to increase over time, and in case of 
return, hospitalizations were more frequent than consultations. Personal psychiatric history and participation in vocational education were the only apparent risk factors of return. Lack of data in the literature about vocational study prevents comparison. Case control and multicentre study would be worthwhile for a more powerful analysis.

For there is no conflict of interest for any of the authors in relation to the subject of this study.

\section{References}

[1] Daniel Bailly, Manuel Bouvard, Françoise Casadebaig, et al. Troubles mentaux : dépistage et prévention chez l'enfant et l'adolescent. [Rapport de recherche] Institut national de la santé et de la recherche médicale(INSERM). 2003, 887 p.

[2] Case S, Case B, Olfson M, Linakis J, and al. Length of stay of pediatric mental health emergency department visits in the United States. J Am Acad Child Adolesc Psychiatry 2011; 50:1110-19.

[3] Daclin C, Dalacin-Jurion V, Humeau V, and al. Young adolescents consulting in general hospital child psychiatric units: descriptive epidemiology, comments and implications. Neuropsychiatr Enfance Adolesc1998; 46: $285-95$

[4]Deboutte D, Smet M, Walraven V, and al. Emergency psychiatric care for children and adolescents Supplement. Health Services Research (HSR). Brussels: Belgian Health Care. Knowledge Centre (KCE). 2010. KCE Reports 135S. D/2010/10.273/52

[5] Dolan M, Fein J. Pediatric and mental health emergencies in the emergency medical services system. Pediatrics2011; $127: 5$.

[6] Richard Y, Saint-André S, Lazartigues A. Sociodemographic features of children and adolescents waiting for consultations at the Child and Adolescent Psychiatry Department of Brest University Hospital. Neuropsychiatr Enfance Adolesc 2008 ; 56 :430-38.

[7] Welniarz B, Medjdoub H. L'hospitalisation temps plein en psychiatrie infanto juvénile : un état des lieux. Neuropsychiatr Enfance Adolesc2007; 55: 401-6.

[8] Blondon M, Perisse D, Unni SKE, and al. Child and adolescent psychiatric emergencies: Evolution over twenty years in a public university hospital. Neuropsychiatr Enfance Adolesc2007; 55: 23-30.

[9] Duverger P, Champion G, Malka J. The child psychiatric emergencies in the paediatric emergency. Revue Française de Psychiatrie et de Psychologie médicale 2000; 40: 19-22.

[10] Gautry P, Chalaux M. An adolescent treatment unit: development and resistance. Arch Pediatr 1998; 5: 839-43.

[11] Jourdain-Menninger D, StrohIMaffesoli H. Enquête sur la prévention et la prise en charge des adolescents et jeunes adultes souffrant de troubles psychiatriques. Rapport $n^{\circ} 2004027$ Paris, Inspection générale des affaires sociales. La documentation Française, 2004 102p.

[12] Stheneur C, Rey C, Alvin P. L'adolescent aux urgences. Médecine thérapeutique/ Pédiatrie1999; 2:369-72.

[13] Choquet M. Suicide et adolescence : acquis épidémiologiques. Médecine thérapeutique/Pédiatrie1998; 1: 337-43.

[14] Stewart SE, Manion IG, Davidson S. Emergency management of the adolescent suicide attempter: a review of the literature. J Adolesc Health 2002; 30: 312-25.

[15] Giraud-Escoffier P. Adolescent en danger aux urgences. Arch PediatrHS1 2012:28-9.

[16] Horassius-Jarrie N, Baldo E. Catch-all psychiatry in emergency ward of general hospital: what of psychiatric emergencies has become? L'Information Psychiatrique 2000; 5: 521-33. 
[17] Nuns N. Les urgences psychiatriques à l’hôpital général. Ann Méd Psychol (Paris) 2005; 163: 607-10.

[18] Seletti B, Launay C, Garnier B, and al. Treating psychiatric emergencies in the emergency room of a university hospital, within a mental health network Ann MédPsychol (Paris) 2001; 159:160-6.

[19] Vidailhet C. Psychiatric emergencies in a hospital for children. Arch Pédiatr 1995; 2: 1131-34.

[20] Rascle C, Digonnet C. A transition between the initial crisis and the psychiatric hospital: The emergency psychiatric ward of Bellevue Hospital, Saint-Etienne, France. La revue des SAMU1997; 2: 92-5.

[21] Gérardin P, Mazet P. Demands in urgency in child psychiatry. Neuropsychiatr Enfance Adolesc 2002; 20 : 557-61.

[22] Rochet T. Hospitalisation des adolescents en psychiatrie. L'Information Psychiatrique 2004; 80 :799-802.

[23] Sills M, Bland S. Summary statistics for pediatric psychiatric visits to US emergency departments, 19931999. Pediatrics 2002; 110: e40.

[24] Starling J, Bridgland K, Rose D. Psychiatric emergencies in children and adolescents: an emergency department audit. Australas Psychiatry 2006; 14: 403-7

[25] Marcos C, Garcia S, Pardillo M, and al. Psychiatric patients in the paediatric emergency department of a tertiary care center: review of a 6-months period. Ann Pediatr (Barc) 2006; 64: 536-41.

[26]Dereau J, Deschietere G, Danailova M, et al. Urgences psychiatriques infanto-juvéniles : revue systématique de trois années de dossiers. Louvain médical 2009; 128: 170-1.

[27] Hansen-Bauer K, Heyerdahl S, Hatling T, and al. Admissions to acute adolescent psychiatric units: a prospective study of clinical severity and outcome. Int J Mental Health Syst 2011 5:1.

[28] Healy E, Saha S, Subotsky F, and al. Emergency presentations to an inner-city adolescent psychiatric service. J Adolesc 2002;25: 397-404.

[29]Laget J, Chanez JM, Dubos PF, Plancherel B, and al. Psychiatric hospitalization of adolescents in Lausanne (Vaud): admissions, paths of care, role and subjective experience. Schweiz Arch Neurol Psychiatr 2002; 153: 272-81.

[30]Pacheco B, Lizana P, Celhay L, and al. Clinical characteristics of children and adolescent hospitalized in a university psychiatric clinic. Rev Méd Chil2007; 135: 751-58.

[31] Park C, McDermott B, Loy J, and al. Adolescent admissions to adult psychiatric units: patterns and implications for service provision. Australas Psychiatry 2011; 19: 345-49.

[32]Podlipski M.-A, Peuch A.-C, Belloncle V, and al. Adolescents consulting at the paediatric emergency room for psychological or psychiatric reasons. Arch Pediatr2013; 21: 7-12.

[33] Stewart C, Spicer M, Babl FE. Caring for adolescents with mental health problems: challenges in the emergency department. J Paediatr Child Health 2006; 42: 726-30.

[34]Zilikis N, Abatzoglou G, Lerodiakonou C (2004) De l'hospitalisation d'adolescents présentant des problèmes psychiatriques : parcours bibliographique et rapport d'une expérience hellénique. L'information Psychiatrique 80:109-22.

[35] Laurent A, Bosson JL, Bost M, and al. Suicide attempts of children and adolescents. About 102 observations in a child psychiatric unit. Neuropsychiatr Enfance Adolesc 1993; 41: 198-205.

[36] Le Galudec M, Richard Y, Saint-André S, and al. The demands of consultation in child psychiatry: Descriptive study over 5 years in a university department. Neuropsychiatr Enfance Adolesc 2011; 59:1-7.

[37] Sperenza M, Laudrin S, Guillemet I, and al. Emergency and crisis intervention in child and adolescent psychiatry. Neuropsychiatr Enfance Adolesc. 2002 ; 50: 562-67.

[38] Sicot F. Urgences pédopsychiatriques : resituer les crises dans le contexte organisationnel de leur survenue. Empan 2009; 3: 53-60.

[39]Nadereau L, Sabbah-Lim, Corruble MN, and al. The use of seclusion room in an adolescent in-patient unit: a retrospective study. Neuropsychiatr Enfance Adolesc 2013; 61:72-80. 
[40]Encarnação R., Moura M, Gomes F, and al. Characterization of the cases referred and consulted in a child and adolescent psychiatry clinic. A retrospective study. Acta Med Port 2011; 24: 925-34.

[41] Lee J, Korczak D. Emergency physician referrals to the paediatric crisis clinic: reasons for referral, diagnosis and disposition. J Can Acad Child Adolesc Psychiatry 2010; 19: 297-302.

[42] Stewart E, Manion I, Davidson S, and al. Suicidal children and adolescents with first emergency room presentations: predictors of six-month outcome. J Am Acad Child Adolesc Psychiatry 2001; 40: 581-87.

[43] Goldstein A, Frosch E, Davarya S, and al. Factors associated with a six month return to emergency services among child adolescent psychiatric patients. Psych Serv 2007; 58:1489-92.

[44]Grupp-Phelan J, Mahajan P, Foltin G, and al. Referral and resource use patterns for psychiatric related visits to pediatric emergency departments. Pediatr Emerg Care 2009; 25: 217-20.

[45] Newton AS, Ali S, Johnson DW, and al. Who comes back? Characteristics and predictors of return to emergency department services for paediatric mental health care. Acad Emerg Med 2010; 17: 177-86.

[46]Christodulu KV, Lichenstein R, Weist MD and al.Psychiatric emergencies in children. Pediatr Emerg Care 2002; 18: 268-70. 
Figure 1: Flow chart of first stays and returns to psychiatric emergency unit

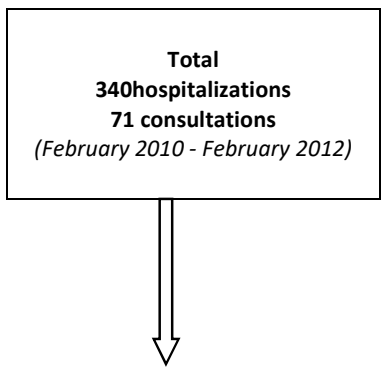

180different patients(First stay taken in account)

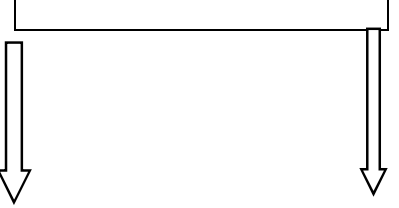

Returns (February 2010 - December 2012):

1stay(February 2010

77 patients

December 2012):

103 patients

rehospitalizations only

1: $n=23 ; 2: n=6 ; 3: n=2 ; 4: n=21: n=15$

49 rehospitalizations consultations and rehospitalization

2: $n=12 ; 3: n=5 ; 4: n=5 ; 5: n=1 ;>5: n=6$

56 consultations; 111 rehospitalizations 
Figure 2: Kaplan-Meyer curve showing cumulative incidence for returns to Psychiatric emergenciesin function of time in days

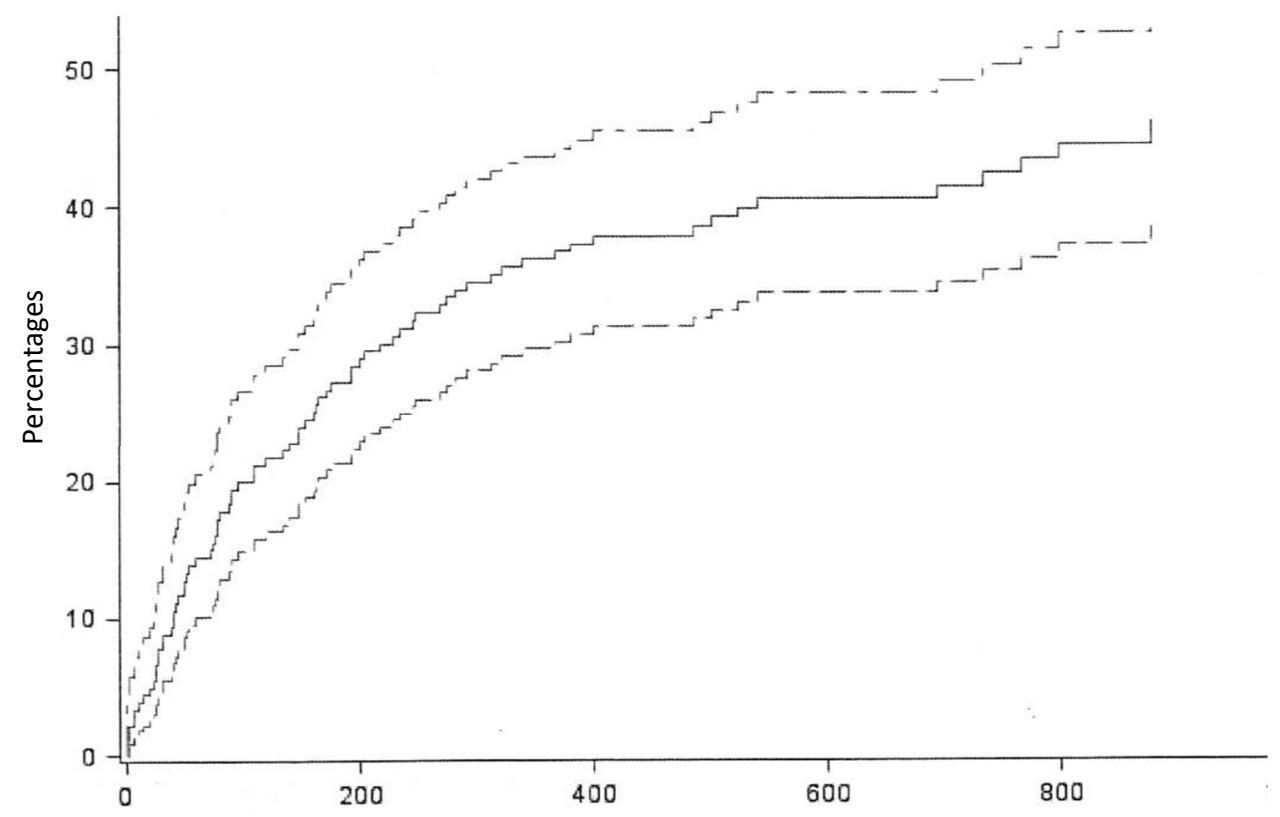

Cumulative incidence $\quad--$ Lowerlimit $\_--\ldots$ Upperlimit 
Table 1. Sociodemographic description of patients

Mean age (years) \pm standard deviation

$N=180$

Sex

$14.8( \pm 1.8)$

Girls

$\mathrm{N}=180$

97(53.9\%)

Boys

83(46.1\%)

Medical history

$\mathrm{N}=171$

$36(21 \%)$

Personal background

Criminal record

$N=180$

Rape/sexual abuse

$9(5 \%)$

Psychiatric history

No history

Consultation in child psychiatric unit

$16(8.9 \%)$

Consultation in psychiatric emergency unit

$\mathrm{N}=178$

$59(33.2 \%)$

105(59\%)

30(16.9\%)

$11(6.2 \%)$

Day care centre

$30(16.9 \%)$

Hospitalization in emergency psychiatric unit

20(11.2\%)

Psychotropic treatment

Family history

$\mathrm{N}=154$

No history

$55(35.7 \%)$

Psychiatric history

$84(54.6 \%)$

Family violence

$28(17.8 \%)$

Ambulatory care

$\mathrm{N}=178$

No ambulatory care

105(59\%)

Educational measures

No

94 (52\%)

Court-ordered placement

50(27.8\%)

Placement by administrative representative

AED

$3(1.7 \%)$

Educational policies in community

$4(2.2 \%)$

Pending

$34(19 \%)$

Substance abuse

No abuse

$N=155$

79 (51\%)

Family situation

Parents together

Parents divorced

Parents separated

62(34.4\%)

40(22.2\%)

$60(33.3 \%)$

One parent dead

$12(6.6 \%)$

Two parents dead

$2(1.1 \%)$

Adopted

$10(5.6 \%)$

Educational level

$\mathrm{N}=174$

Dropped out of school

29(16.7\%)

Conventional education

106(60.9\%)

Vocational education

$17(9.8 \%)$

Medical and pedagogic institution

$9(5.2 \%)$

Medical, pedagogic, psychotherapeutic institutio

$13(7.5 \%)$


Table 2: Synthesis of hospitalisations and orientation at discharge

\begin{tabular}{|c|c|c|c|c|c|}
\hline Reasons for hospitalization & $\mathrm{N}=340$ & Reasons for stay in hospital & $\mathrm{N}=340$ & Orientation & $N=336$ \\
\hline Destructive behaviours & $130(38,23 \%)$ & Sedation of crisis & $173(51 \%)$ & Return home & $201(60 \%)$ \\
\hline Suicidal ideation & $57(16,76 \%)$ & Legal or administrative proceeding & $3(0,8 \%)$ & Hospitalization in child psychiatry unit & $56(16,6 \%)$ \\
\hline Suicide attempt & $50(14,7 \%$ & Medication adjustment & $158(46,4 \%)$ & Psychological counselling & $21(6,2 \%)$ \\
\hline Runaway & $33(9,7 \%)$ & Paraclinical examination/s & $6(1,7 \%)$ & Sheltered accommodation & $6(1,8 \%)$ \\
\hline Scarification & $23(7 \%)$ & & & Wait before hospitalization & $13(3,8 \%)$ \\
\hline Anxiety & $20(5,8 \%)$ & Adverse events & & Medico social device & $7(2 \%)$ \\
\hline Alcohol abuse & $14(4 \%)$ & Suicide attempt & $3(1 \%)$ & Prevention of suicide attempt & $12(3,5 \%)$ \\
\hline Delusional ideation & $13(3,8 \%)$ & Runaway & $7(2 \%)$ & Adult psychiatry & $20(6 \%)$ \\
\hline
\end{tabular}


Table 3 : factors for returns to psychiatric emergency unit : univariate and multivariate analysis

\begin{tabular}{|c|c|c|c|c|c|c|}
\hline \multirow[t]{2}{*}{ Sociodemographic data } & \multicolumn{3}{|c|}{ Univariate analysis } & \multicolumn{3}{|c|}{ Multivariate analysis } \\
\hline & Return & No-return & $\mathbf{p}$ & Relative risk & $95 \% \mathrm{Cl}$ & $\mathbf{p}$ \\
\hline \multicolumn{7}{|l|}{$\operatorname{sex}$} \\
\hline Girls & $35(45.5 \%)$ & $48(46.6 \%)$ & 0.88 & & & \\
\hline \multicolumn{7}{|l|}{ boys } \\
\hline \multicolumn{7}{|l|}{ Psychiatric history } \\
\hline No history & $17(28.8 \%)$ & 47 (71.2\%) & $0.006 *$ & 2.505 & $1.166-5.832$ & 0.0186 \\
\hline Consultation in child psychiatric unit & $56(53.3 \%)$ & $49(46.7 \%)$ & $0.001 *$ & & & \\
\hline Consultation in psychiatry emergency unit & $17(28.8 \%)$ & $13(43.3 \%)$ & 0.098 & & & \\
\hline Hospitalization in child psychiatry unit & $19(63.3 \%)$ & $11(36.7 \%)$ & $0.015^{*}$ & & & \\
\hline Hospitalization in emergency psychiatric unit & $11(55 \%)$ & $9(45 \%)$ & 0.25 & & & \\
\hline Day care centre & $2(18.2 \%)$ & $9(81.8 \%)$ & 0.12 & & & \\
\hline Rape/sexual abuse & $6(37.5 \%)$ & $10(62.5 \%)$ & 0.65 & & & \\
\hline Criminal record & $2(22.2 \%)$ & $7(77.8 \%)$ & & & & \\
\hline \multicolumn{7}{|l|}{ Family history } \\
\hline No & $22(40 \%)$ & $33(60 \%)$ & 0.44 & & & \\
\hline Psychiatric history & $40(47.6 \%)$ & $44(52.4 \%)$ & 0.34 & & & \\
\hline Family violence & $15(53.6 \%)$ & $13(46.4 \%)$ & 0.24 & & & \\
\hline \multicolumn{7}{|l|}{ Educational measures } \\
\hline No measures & $34(36.2 \%)$ & 60 (63.9\%) & 0.06 & & & \\
\hline Court-ordered placement & $28(56 \%)$ & $22(44 \%)$ & $0.0262^{*}$ & & & \\
\hline \multicolumn{7}{|l|}{ Educational level } \\
\hline Dropped out of school & $11(38 \%)$ & $18(62 \%)$ & 0.58 & & & \\
\hline Vocational education & $11(64.7 \%)$ & $6(35.3 \%)$ & $0.05^{*}$ & 3.395 & 1.2777-12.129 & $0.0163^{*}$ \\
\hline \multicolumn{7}{|l|}{ Substance abuse } \\
\hline No abuse & $31(29.2 \%)$ & $48(60.8 \%$ & 0.18 & & & \\
\hline \multicolumn{7}{|l|}{ Ambulatory care } \\
\hline No ambulatory care & $41(39 \%)$ & $64(61 \%)$ & 0.17 & & & \\
\hline Antipsychotic drugs & $29(59 \%)$ & $20(40.8 \%)$ & $0.008^{*}$ & & & \\
\hline \multicolumn{7}{|l|}{ Treatment at discharge } \\
\hline No treatment & $6(21.4 \%)$ & $22(78.6 \%)$ & $0.0129 *$ & & & \\
\hline \multicolumn{7}{|l|}{ Reasons for referral } \\
\hline Suicide attempt & $11(29 \%)$ & $27(71 \%)$ & $0.05^{*}$ & & & \\
\hline Anxiety & $5(37.5 \%)$ & $9(64.3 \%)$ & 0.6 & & & \\
\hline scarification & $6(43 \%)$ & $9(64.3 \%)$ & 1 & & & \\
\hline Destructive behaviour & $37(47.7 \%)$ & $44(54.3 \%)$ & 0.5 & & & \\
\hline Runaway & $9(43 \%)$ & $12(57 \%)$ & 1 & & & \\
\hline Alcohol abuse & 4 (36.4\%) & $7(63.6 \%)$ & 0.8 & & & \\
\hline Delusional ideation & $5(45.5 \%)$ & 6 (54.6\%) & 1 & & & \\
\hline Suicidal ideation & 21 (49\%) & 22 (51\%) & 0.36 & & & \\
\hline contention & $23(45 \%)$ & 28 (54.9\%) & & & & \\
\hline
\end{tabular}


Table 4 Cumulative incidence of returns at 6 months, 1 and 2 years $(n=77)$

\begin{tabular}{|c|c|c|c|}
\hline Period & Cumulative incidence of returns & \% of return & Confidence interval \\
\hline \multirow{3}{*}{ At 6 months } & hospitalizations and consultations & 27.2 & {$[23.9-30.5]$} \\
\cline { 2 - 4 } & hospitalizations & 20.0 & {$[17-23]$} \\
\cline { 2 - 4 } & consultations & 12.2 & {$[9.8-14.6]$} \\
\hline \multirow{3}{*}{ At 1 year } & hospitalizations and consultations & 36.1 & {$[32.5-39.7]$} \\
\cline { 2 - 4 } & hospitalization & 28.9 & {$[25.5-32.3]$} \\
\cline { 2 - 4 } & consultations & 19.4 & {$[16.4-22.3]$} \\
\hline \multirow{3}{*}{ At 2 years } & hospitalizations and consultations & 42.8 & {$[37.7-45.2]$} \\
\cline { 2 - 4 } & hospitalizations & 32.9 & {$[29.3-36.5]$} \\
\hline & consultations & 23,2 & {$[20-26,4]$} \\
\hline
\end{tabular}

